\title{
BIONOMICS AND SYSTEMATICS OF THE ORIENTAL ANOPHELES SUNDAICUS COMPLEX IN RELATION TO MALARIA TRANSMISSION AND VECTOR CONTROL
}

\author{
ISABELLE DUSFOUR, RALPH E. HARBACH, AND SYLVIE MANGUIN \\ Institute of Research for Development, Center of Biology and Management of Populations, Campus International de Baillarguet, \\ Montferrier sur Lez, France; Department of Entomology, The Natural History Museum, London, United Kingdom
}

\begin{abstract}
The taxonomic history, distribution, bionomics, systematics, and vector control strategies for the Anopheles sundaicus complex are reviewed in relation to malaria epidemiology. The lack of data on the bionomics, insecticide resistance, and vector capacity, as well as the general lack of surveillance and monitoring of potential vector populations, make the development of targeted control measures problematic. It will be necessary to elucidate, characterize and identify all members of the complex to determine their distributions, disease relationships, ecologic relationships, and resistance to insecticides. This knowledge is essential for epidemiologic studies, the design and implementation of appropriate vector control measures, and the development of strategies for monitoring and assessing the potential risk of malaria outbreaks due to members of the complex.
\end{abstract}

\section{INTRODUCTION}

Malaria control strategies aim to decrease human morbidity and mortality by limiting parasite transmission. ${ }^{1}$ The identification of vector species and knowledge of their ecology and behavior is essential for epidemiologic studies and the design and implementation of appropriate vector control strategies. Among morphologically indistinguishable anopheline species, distinct ecoethologic differences have been used to identify putative species associated with malaria transmission. ${ }^{2-4}$ These putative species are now recognized as distinct genetic species.

In southeast Asia, vector studies and malaria control are focused mainly on three major species complexes: Anopheles dirus Peyton \& Harrison, An. minimus Theobald, and An. sundaicus Rodenwaldt. The An. dirus and An. minimus complexes are well known because they are widespread throughout southeast Asia, whereas the An. sundaicus complex has been investigated to a much lesser degree because the species occur mainly in coastal areas. ${ }^{5-15}$ The ecology, behavior, and/ or vectorial capacity of An. sundaicus s.l. have been described for populations in India, Indonesia, Malaysia, Vietnam, Myanmar, Thailand, and Cambodia. ${ }^{16-20}$ However, comparisons of the main characteristics of populations across the distribution of the taxon are wanting. ${ }^{21}$

The probability that An. sundaicus represents a complex of species was hypothesized on the basis of ecoethologic differences and isolation of populations on the coastal areas and islands of southeast Asia. ${ }^{11,22,23}$ The recent use of genetic and molecular tools confirmed the genetic isolation of species that comprise the An. sundaicus complex. ${ }^{24,25}$ Considered an efficient malaria vector taxon, An. sundaicus s.l. has been a principal target of mosquito control programs even though links between biologic characteristics and vectorial capacity have not been clearly defined.

The aim of this report is to consolidate available information about the An. sundaicus complex as a foundation for further investigation and a better understanding of the individual species across their ranges of distribution. Unless otherwise noted, An. sundaicus refers to An. sundaicus s.l. in the discussion of this report.

\section{DISTRIBUTION}

The distribution of An. sundaicus includes coastal areas (Figure 1) from northeastern India to southern Vietnam (be- low the 11th parallel), south to the Nicobar, Andaman, and Indonesian islands. ${ }^{24,26,27}$ The taxon occurs in southern $\mathrm{Su}$ lawesi, ${ }^{27,28}$ but is absent from The Philippines ${ }^{29,30}$ and has not been reported from southern Borneo ${ }^{31,32}$ (Figure 1). It has been observed in Pakistan ${ }^{33-35}$ and two localities in northwestern India, ${ }^{36}$ but these observations require verification.

Environmental changes due to human activities seem to be causing the disappearance of the taxon from coastal areas. ${ }^{5,11,14,37,38}$ Recent field surveys in northwestern peninsular Malaysia and the eastern coastal region of India (Figure 1) suggest that $A n$. sundaicus no longer occurs there. ${ }^{31,39,40}$ Earthen embankments were built in peninsular Malaysia to prevent intrusion of sea water ${ }^{41}$ and profound ecologic and salinity changes occurred in India, ${ }^{37}$ which probably altered or eliminated potential larval habitats. In other countries such as Pakistan, field records are not recent and the occurrence of An. sundaicus is uncertain. In addition, local populations of An. sundaicus are known to have a fluctuating, patchy distribution in space and time, changing through the year in response to the availability of adequate breeding sites. ${ }^{27,42,43} \mathrm{In}$ general, the distribution of An. sundaicus on the coastal areas and islands of southeast Asia is poorly known due to a paucity of available data.

\section{BIONOMICS: FIRST EVIDENCE OF A SPECIES COMPLEX}

Immature stages. The immature stages of $A n$. sundaicus inhabit sunlit bodies of stagnant water, including ponds with vegetation and floating algae,${ }^{14,42}$ swamps, ${ }^{11}$ mangrove, ${ }^{18}$ wells, rockpools, ${ }^{22,31}$ and particularly shrimp/fish ponds along the coast or irrigated by inland sea water canals, ${ }^{14,15,28,30,32,44}$ which are reported as favorable habitats in Vietnam and Indonesia. Sea water aquaculture was known during the 18th century in Jakarta to be favorable for malarial mosquitoes, which were most likely An. sundaicus. ${ }^{45}$ Lagoons and creeks $^{11,15,31,46-48}$ and blocked river mouths ${ }^{8,16}$ are also favorable sites for An. sundaicus larvae. Since the majority of suitable larval habitats are provided with saline water from the sea, An. sundaicus has been described as mainly a brackish water breeder in coastal areas. ${ }^{14,15,49}$ However, the taxon has been found in inland sites with either brackish or freshwater. In southern Vietnam, where no permanent freshwater breeding sites have been encountered, sea water canals contribute saline water to larval habitats. ${ }^{30}$ In contrast, An. sun- 


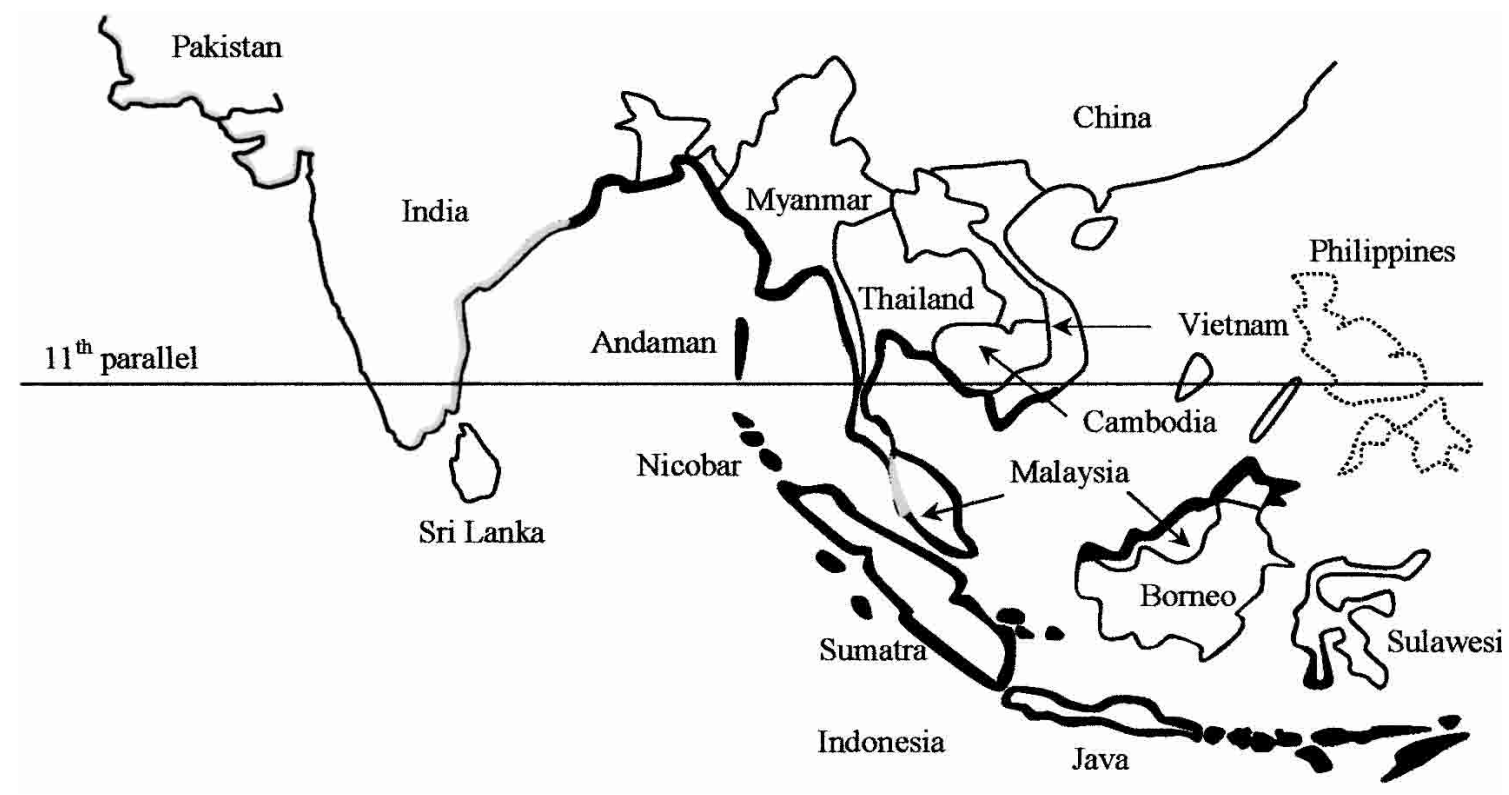

Figure 1. Distribution of the Anopheles sundaicus complex. Coastal areas in marked in black represent the currently recognized distribution. Gray zones are areas where An. sundaicus reportedly disappeared. The taxon is absent or has never been recorded in the uncolored areas.

daicus larvae breed in inland freshwater ponds in India, ${ }^{31,50}$ Car Nicobar island, ${ }^{46}$ peninsular Malaysia, ${ }^{51}$ Sarawak (Malaysian Borneo), ${ }^{22}$ and Indonesia. ${ }^{15,24,28}$ Published data indicate that larvae tolerate salinity ranging from $0 \%$ to $11 \%$ (Figure 2), i.e., from freshwater $(<0.05 \%)$ to much greater concentrations than sea water $(3.5 \%)$. Over time, salinity in ponds changes as a result of rainfall, inundation by sea water, and evaporation. ${ }^{27,30}$ Soeparno and Lair ${ }^{15}$ and Kikuchi and others $^{52}$ noted that the levels of salinity in coastal habitats are affected by tidal movements. Therefore, any comparison of salinity must be done cautiously, as indicated by the different optimal ranges shown in Figure 2. Phan $^{30}$ noted a positive correlation between salinity and vector density, with peak density at the start of the rainy season. This correlation shows the importance of salinity tolerance in larval development. In addition, Collins and others ${ }^{28}$ noted that An. sundaicus females in southern Sulawesi readily oviposit in freshwater if no brackish water sites are available.

The wide range from freshwater to saline breeding sites was one of the differences that led mosquito workers to hypothesize that An. sundaicus was a species complex. ${ }^{22}$ Either different species accounted for observed ecologic differences or one euryhaline species was tolerant to a wide range of salinity.

Compared with salinity, the $\mathrm{pH}$ of larval habitats is not so variable, ranging from 7 to 8.5 in India, Vietnam, and Java (Indonesia). $9,14,31,47$

Filamentous floating algae and aquatic plants appear to be crucial for the development of An. sundaicus larvae. ${ }^{14,47}$ Aquatic flora supplies food (micro-algae and bacteria) and protection against predators. ${ }^{15,53,54}$ In Bengal, India, Iy-

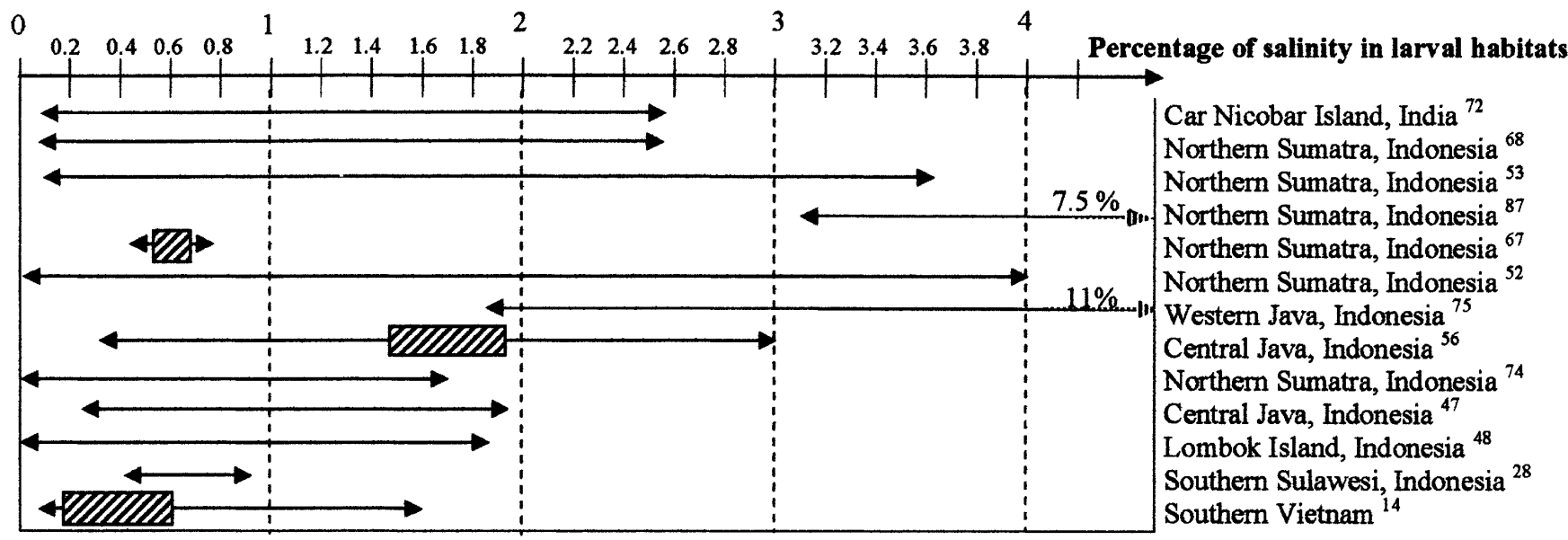

FIGURE 2. Range and optimal range of salinity reported for breeding sites of Anopheles sundaicus in various countries. 
enger $^{55}$ found a direct relationship between surface algae together with submerged vegetation and breeding sites. Exceptions include sites on the Coral Beach of India ${ }^{32}$ and rockpools on Pandan Beach in the Lundu District of Sarawak (Malaysian Borneo), ${ }^{22}$ where no vegetation was present. Freshwater plants such as Salvinia sp. ${ }^{53}$ and Eichhornia crassipes (water hyacinth) ${ }^{52}$ are associated with the absence of An. sundaicus larvae, but since immature stages occur in freshwater habitats these plants seem to be more a barrier to oviposition than indicators of unfavorable breeding places. $^{52}$

Adult behavior. Differences in adult behavior are also indicators of species diversity. Anopheles sundaicus exhibits both endophagy and exophagy. It is mainly endophilic and anthrophilic, but also exhibits exophily and zoophily (Table 1). Indoor application of insecticide for vector control showed the presence of exophagic, exophilic, and zoophilic An. sundaicus in areas of the Nicobar islands and Vietnam where the vector was previously known to be endophagic, endophilic, and anthropophilic. ${ }^{11,30}$ Females exhibit a peak of biting activity from 8:00 PM to 3:00 AM depending on locality. Adventitious biting in dark houses during the day has been observed in Vietnam, ${ }^{10,14}$ but humans are generally at higher risk of being bitten indoors while sleeping during the night. Anopheles sundaicus is capable of flying long distances, ranging from 1.6 to $9 \mathrm{~km},{ }^{13,27,40,56}$ but blood feeding depends on the location and availability of hosts and insecticide pressure.

Due to its ecologic and behavioral plasticity, An. sundaicus has adapted to a range of coastal and inland environmental situations. The main requirement is the presence of sunlit breeding sites with fresh or brackish water, floating algae, and non-invasive vegetation in coastal areas and on islands. Adult females are mainly anthropophilic and endophilic. Comparison of the biology of $A n$. sundaicus with that of the more intensely studied An. gambiae complex in Africa or the $A n$. minimus complex in Asia suggested the existence of a species complex in the absence of other evidence. Investigation based on genetic tools confirmed that An. sundaicus is a complex of species.

\section{GENETIC CONFIRMATION OF A SPECIES COMPLEX}

Genetic tools were used to establish beyond doubt that $A n$. sundaicus is a species complex. Cytogenetic and enzymatic studies were first carried out on populations from Thailand and Indonesia (Java and Sumatra) that resulted in the discovery of three forms, informally designated forms A, B, and C. ${ }^{24,25}$ A fourth cytotype named D was identified on Car Nicobar Island. ${ }^{57}$ Form A was collected from coastal areas of Thailand, Sumatra, and Java. Form B was mainly collected in the freshwater sites at South Tapanuli in northern Sumatra in association with form $\mathrm{A}$, where it comprised $92.9 \%$ of the females captured in September 1993 and 87.5\% in September 1994. Form B was also found with form A in a brackish water area at Purwojero in southcentral Java, where it comprised $9.9 \%$ of the collections. Form $\mathrm{C}$ was only found in one coastal locality at Asahan in northeastern Sumatra, where it occurred in sympatry with both species A and B (48.4\% A, 14.5\% B, and $37.1 \% \mathrm{C})$. The presence of forms $\mathrm{A}$ and $\mathrm{B}$ at both freshwater and brackish water sites seemed to dispel the hypothesis that populations with different ecologic requirements might represent different species. In fact, use of the cytochrome $\mathrm{b}$ and cytochrome oxidase I mitochondrial markers later showed that mosquitoes reared from an inland freshwater pond near Miri and a brackish water rock pool on the shore of the South China Sea in the Lundu District of Sarawak were the same species. ${ }^{58}$ Based on the formal taxonomic recognition and definition of An. sundaicus s.s. as the species encountered in Miri and Lundu, ${ }^{26}$ Dusfour and others $^{58}$ demonstrated that form $\mathrm{A}$ in the coastal areas of Vietnam and Thailand is a different genetic species of An. sundaicus complex.

The genetics of An. sundaicus are poorly explored, but the limited chromosomal, isozyme, and molecular studies confirmed that the taxon is a species complex. However, the molecular studies were based on some different populations than the chromosomal and isozyme studies, and the results cannot be correlated entirely. Further investigation using the

TABLE 1

Behavior of Anopheles sundaicus observed in different localities

\begin{tabular}{|c|c|c|c|c|}
\hline Country & Trophic preference & Resting preference & Biting preference & Source \\
\hline Cambodia & Exophagy & & Anthropophily & Chow $1970^{16}$ \\
\hline Cambodia & Exophagy/endophagy & Endophily & Zoophily/anthropophily & Webster $2000^{49}$ \\
\hline India (Nicobar/Andaman) & Endophagy & Endophily & Anthropophily & Covell $1927^{70}$ \\
\hline India (Andaman/Orissa) & & Endophily & Anthropophily & Covell and Singh $1942^{71}$ \\
\hline India (Nicobar/Andaman) & Exophagy & Exophily & Zoophily/anthropophily & Kalra $1978^{11}$ \\
\hline India (Nicobar) & & & Zoophily & Kumari and others $1993^{61}$ \\
\hline India (Nicobar) & Endophagy & Endophily & & Kumari and Sharma $1994^{72}$ \\
\hline India (West Bengal) & & & Zoophily/anthropophily & Nandi and others $2000^{73}$ \\
\hline Indonesia (northern Sumatra) & Exophagy/endophagy & Exophily & & Ikemoto $1982^{74}$ \\
\hline Indonesia (western Java) & Endophagy & Endophily & & Akiyama $1984^{75}$ \\
\hline Indonesia (central Java) & Endophagy & Endophily & & Kirnowardoyo and Yoga $1987^{47}$ \\
\hline Indonesia (Sulawesi) & Endophagy & Endophily & Anthropophily & Collins and others $1979^{28}$ \\
\hline Malaysia & Exophagy & Exophily & Zoophily & Moorhouse and Wharton $1965^{76}$ \\
\hline Malaysia & Exophagy & & Anthropophily & Chow $1970^{16}$ \\
\hline Malaysia (Sarawak) & Endophagy & & & Chow $1970^{16}$ \\
\hline Thailand & & Exophagy & Zoophily & Gould and others $1966^{59}$ \\
\hline Vietnam & & Endophily & Anthropophily & Giang and others $1980^{77}$ \\
\hline Vietnam & & Exophily & & Phan $1998^{30}$ \\
\hline
\end{tabular}


same markers and the same populations is required to clarify the number of species that comprise the complex.

\section{ANOPHELES SUNDAICUS: A MALARIA VECTOR}

Differences in the adult behavior and larval habitats of $A n$. sundaicus are indicative of an increased risk of contact with humans. Anopheles sundaicus is considered as either a major vector or secondary vector of malaria depending on region and country. ${ }^{13,54}$ It was previously regarded as a secondary vector in Thailand. ${ }^{18,59}$ However, because of its occurrence close to tourist sites, it is now considered as a potential major vector. ${ }^{17}$ In contrast, it has been regarded as the principal vector in coastal areas of India ${ }^{23}$, Vietnam, ${ }^{14}$ and Indonesia. ${ }^{15,48}$ Kirnowardoya and Yoga ${ }^{47}$ observed that malaria transmission at Chilacap on Java fluctuated widely, not only from year to year, but also from locality to locality during the same year. In the meantime, An. sundaicus was responsible for local epidemics in Orissa, India from 1930 to $1940,{ }^{31}$ in Calcutta in $1936,{ }^{60}$ in Vietnam from 1965 to $1985,{ }^{30}$ and in Indonesia in $1985 .{ }^{47}$ Outbreaks in Indonesia are also linked to the increase of shrimp and fish farming. ${ }^{32,45}$ The development of such farms induced first an increase in mosquito densities and second a greater proximity of mosquitoes to human hosts in important social and economic areas. ${ }^{15}$ Knowledge of fluctuations in densities of An. sundaicus is crucial for understanding malaria transmission in inhabited coastal areas. This taxon has been found in large numbers in certain areas of central Java (Indonesia) and Nicobar Island where the incidence of malaria is very low. ${ }^{56,61}$ Huehne $^{62}$ found that although An. sundaicus occurred in high densities in coastal areas of Malaysia, it was not involved in malaria transmission. Coosemans and others ${ }^{29}$ showed a null sporozoite rate in $\mathrm{Bac}$ Lieu Province of southern Vietnam where humans receive an average of 12.78 bites from An. sundaicus per hour. Coosemans and others ${ }^{63}$ explained that a drastic increase of density can induce a reduction in transmission as a result of decreased mosquito longevity whereby sporogonic development of malaria plasmodia cannot be completed. This situation could occur anywhere where An. sundaicus occurs in very high densities. Conversely, Poolsuwan ${ }^{64}$ reported that a low sporozoite rate is compensated for by high density in areas of trans- mission. However, no studies have examined mosquito densities in relation to decrease in sporozoite rate. Additionally, few recent data are available for sporozoite rates in An. sundaicus, and published observations show considerable disparity in different localities and countries (Table 2).

Apart from the transmission of human malarial parasites, An. sundaicus has been found to transmit monkey malaria in the Andaman Islands. ${ }^{12}$ Although previously defined as anthropophilic, endophagic, and endophilic, Kalra ${ }^{12}$ found that An. sundaicus was more zoophilic, exophagic, and exophilic. Sporozoite detection showed that An. sundaicus was transmitting Plasmodium cynomolgi, which is closely related to $P$. vivax, to both monkeys and humans. This is interesting in view of laboratory studies that have shown that An. sundaicus is not able to transmit $P$. gonderi ${ }^{65}$ or other parasites on Nicobar Island. ${ }^{9}$

The role of An. sundaicus in malaria transmission has been defined as heterogeneous. As such, it poses a threat for malaria epidemics and endemism in areas of economic development, notably shrimp farming and tourism. Consequently, it is important to monitor populations to better define the actual or potential role of An. sundaicus in malaria transmission. The ecologic and behavioral plasticity of this taxon poses difficulties for the development of appropriate vector control strategies.

\section{CONTROL STRATEGIES}

Eradication of $A n$. sundaicus was included in the antimalarial programs undertaken in many southeast Asian countries in the 1950s. The strategy was based on the application of DDT inside houses. ${ }^{7,13,30}$ The unforeseen consequence was the rapid resistance of mosquitoes to DDT (Table 3). However, An. sundaicus remained susceptible in a few malaria foci of India. 9,31 Other insecticides were used in areas where DDT resistance occurred, but few records report whether An. sundaicus has developed resistance. To circumvent or decrease the extent of resistance and avoid wasteful indoor spraying where An. sundaicus is exophilic or exophagic, control efforts focused on environmental alteration of breeding sites, particularly in Indonesia. ${ }^{42}$ The elimination of brackish water habitats by drainage was effective in decreasing vector den-

TABLE 2

Sporozoite rates observed in different populations of Anopheles sundaicus

\begin{tabular}{|c|c|c|c|}
\hline Country & Year & $\begin{array}{c}\text { Sporozoite rate } \\
(\%)\end{array}$ & Source \\
\hline Bangladesh & 1952 & 4.3 & Nasiruddin $1952^{33}$ \\
\hline Cambodia & 1977 & 0.4 & Klein $1977^{19}$ \\
\hline India (Calcutta) & 1936 & 3.6 & Sen $1938^{60}$ \\
\hline India & 1948 & 2.7 & Nagpal and Kalra $1997^{31}$ \\
\hline Indonesia (Sulawesi) & 1953 & 0.04 & Bonne-Webster and Swellengrebel $1953^{78}$ \\
\hline Indonesia (Sulawesi) & 1973 & 0.07 & Collins and others $1979^{28}$ \\
\hline Indonesia (Java) & $1952-56$ & $0.04-0.3$ & Sundaraman and others $1957^{56}$ \\
\hline Indonesia (Flores) & 1991 & 4.2 & Marwoto and Arbani $1991^{79}$ \\
\hline Malaysia (Sabah Province) & 1957 & 1.65 & Malaria Report 1957 cited in Chow $1970^{16}$ \\
\hline Thailand & 1966 & 0 & Gould and others $1966^{59}$ \\
\hline Vietnam (Go Cong Province) & 1961 & 2.9 & Phan $1998^{30}$ \\
\hline Vietnam (Go Cong Province) & 1971 & 4.4 & Phan $1998^{30}$ \\
\hline Vietnam (Ho Chi Minh Province) & 1968 & 1.03 & Nguyen Tang Am and others $1993^{14}$ \\
\hline Vietnam (Mekong Delta) & 1968 & 0.18 & Hien $1968^{80}$ \\
\hline Vietnam (Tra Vinh Province) & 1975 & 2.7 & Giang and others $1980^{77}$ \\
\hline Vietnam (Bac Lieu Province) & 1998 & 0 & Coosemans and others $1998^{29}$ \\
\hline
\end{tabular}


TABLE 3

Chronologic listing of insecticide resistance in different populations of Anopheles sundaicus

\begin{tabular}{|c|c|c|c|}
\hline Date & Country & Resistance status & Source \\
\hline 1954 & Indonesia & DDT resistant & Crandell $1954^{81}$ \\
\hline 1956 & Indonesia (Java) & DDT resistant & Chow $1970^{16}$ \\
\hline 1962 & Malaysia (Sabah) & Dieldrin resistant, DDT susceptible & Chow $1970^{16}$ \\
\hline 1973 & Indonesia (Sulawesi) & DDT susceptible & Giang and others $1980^{77}$ \\
\hline 1976 & Indonesia & DDT and dieldrin resistant & WHO $* 1976^{82}$ \\
\hline 1978 & India & DDT resistant & Kalra $1978^{11}$ \\
\hline 1979 & Singapore & $\begin{array}{l}\text { Susceptible to } 3 \text { organochlorines, } 5 \\
\text { organophosphates, and } 1 \text { pyrethroid }\end{array}$ & Ong Keng Ho and others $1981^{83}$ \\
\hline 1989 & India (Kamorta Island) & DDT susceptible, temephos susceptible & Das and others $1989^{9}$ \\
\hline 1985 & Vietnam & DDT resistant, others susceptible & Nguyen Tang Am and others $1993^{14}$ \\
\hline 1985 & Indonesia (Java) & DDT susceptible & Kirnowardoyo $1985^{84}$ \\
\hline 1987 & Indonesia (central Java) & DDT resistant & Kirnowardoya and Yoga $1987^{47}$ \\
\hline 1994 & Vietnam & DDT resistant, others susceptible & Gornostaeva and others $1994^{85}$ \\
\hline 1997 & India & DDT susceptible & Nagpal and Kalra $1997^{31}$ \\
\hline 2000 & Indonesia & DDT resistant & Webster $2000^{86}$ \\
\hline
\end{tabular}

$*$ WHO $=$ World Health Organization.

sities. ${ }^{15}$ The main idea of such drainage is to confine the tidal influence to well-kept channels where the movement of water will prevent the breeding of An. sundaicus. ${ }^{40}$ Bunds and sluice gates built at the outlet of main drains are commonly used methods to prevent the invasion of seawater, ${ }^{40}$ but such constructions are expensive. Fortunately, control measures against An. sundaicus coincide with the complete exclusion of salt water in agriculture. ${ }^{40}$ Efforts to eliminate vegetation and algae from ponds and plant mangrove in lagoons were also undertaken. However, these practices required ongoing attention and follow-up. ${ }^{55,66}$ Takagi and others ${ }^{67}$ attempted to suppress larval development in western Java by shading fishponds with the leaves of Nipa palm, or by adding larvivorous fish to these habitats. This strategy was cheap, easy to develop, and efficient, but it required the monthly renewal of Nipa palm leaves and was not suitable for fisheries and large ponds. Larvivorous fish were used successfully in combination with Bacillus thuringiensis israelensis and chemical larvicides in northern Sumatra, ${ }^{42}$ and Schaefer and Kirnowardoyo $^{54}$ introduced B. thuringiensis H-14 in western Java for the successful control of An. sundaicus. Unfortunately, subsequent application was inefficient. ${ }^{66}$ Similar trials were undertaken with B. sphaericus 2362 in Thailand. ${ }^{17}$ All of these strategies were considered successful in controlling An. sundaicus, ${ }^{13,42,68}$ but they were impractical for large-scale application at national levels.

\section{CONCLUSIONS}

Due to its plasticity and capacity to transmit malaria, members of the An. sundaicus complex represent a threat to coastal and island populations of humans in southeast Asia. The capacity of An. sundaicus to develop in seawater, various concentrations of brackish water, and freshwater is not linked to a particular species, but to an ability of the species to adapt to available sites. However, its presence is restricted along the coast, supporting the hypothesis of larval tolerance to freshwater rather than a wide degree of adaptability. The capacity to develop in a range of habitats from freshwater to seawater is not unusual in anopheline mosquitoes that is known for other species, such as An. pseudopunctipennis. ${ }^{69}$ Moreover, the lack of recent data on the bionomics, insecticide resis- tance, and vector capacity, as well as the general lack of surveillance and monitoring of potential vector populations, make the development of targeted control measures problematic. The results of recent molecular and phylogenetic analyses of the An. sundaicus complex ${ }^{58}$ will foster further study of these mosquitoes. The next step should be the elucidation, characterization, and identification of all members of the complex that includes four identified species: An. sundaicus s.s. and species A confirmed by molecular markers ${ }^{58}$ and species B and C. ${ }^{24,25}$ Such work is needed to determine the distributions, disease relations, environmental characteristics, and insecticide resistance of the individual species. This knowledge is essential for epidemiologic studies, the design and implementation of appropriate vector control measures, and the development of strategies for monitoring the spatiotemporal fluctuations of An. sundaicus needed to assess the potential risk of malaria outbreaks.

Received February 23, 2004. Accepted for publication April 4, 2004.

Authors' addresses: Isabelle Dusfour, Institute of Research for Development, Center of Biology and Management of Populations, Campus International de Baillarguet, CS30016, Montferrier sur Lez 34988, France, Telephone: 33-499-623-328, Fax: 33-499-623-345, Email: Dusfour@mpl.ird.fr. Ralph E. Harbach, Department of Entomology, The Natural History Museum, Cromwell Road, London SW7 5BD, United Kingdom, Telephone: 44-2-079-425-768, Fax: 44 2-07- 425-229, E-mail: R.Harbach@nhm.ac.uk. Sylvie Manguin, Institute of Research for Development, Center of Biology and Management of Populations, Campus International de Baillarguet, CS30016, Montferrier sur Lez 34988, France, Telephone: 33-499-623-327, Fax: 33-499-623-345, E-mail: Manguin@mpl.ird.fr.

\section{REFERENCES}

1. Declan B, 1997. Time to put malaria on the global agenda. Nature 386: 535-541.

2. Green CA, Gass RF, Munstermann LE, Baimai V, 1990. Population-genetic evidence for two species in Anopheles minimus in Thailand. Med Vet Entomol 4: 25-34.

3. Della Torre A, Costantini C, Besansky NJ, Caccone A, Petrarca V, Powell JR, Coluzzi M, 2002. Speciation within Anopheles gambiae - the glass is half full. Science 298: 115-117.

4. van Bortel W, Trung HD, Manh ND, Roelants P, Verle P, Coosemans M, 1999. Identification of two species within the Anopheles minimus complex in northern Vietnam and their behavioural divergences. Trop Med Int Health 4: 257-265. 
5. Bang YH, 1985. Implication in the Control of malaria vectors with insecticides in tropical countries of South-East Asia Region. Part II - Consequences of insecticide use. J Commun Dis 17: $300-310$.

6. Barcus MJ, Laihad F, Sururi M, Sismadi P, Marwoto H, Bangs MJ, Baird JK, 2002. Epidemic malaria in the Menoreh Hills of Central Java. Am J Trop Med Hyg 66: 287-292.

7. Brandling-Bennett AD, Doberstyn EB, Pinichpongse S, 1981. Current epidemiology of malaria in Southeast Asia. Southeast Asian J Trop Med Public Health 12: 289-297.

8. Chooi CK, 1985. Status of malaria vectors in Malaysia. Southeast Asian J Trop Med Public Health 16: 133-138.

9. Das SC, Nath DR, Bhuyan M, Das NG, Baruah I, Talukdar PK, 1989. Studies on malaria and filariasis vectors in Kamorta and Great Nicobar Islands. Indian J Malariol 26: 153-157.

10. Hair JD, 1973. Day-time indoor resting anophelines of the delta region of Vietnam. Mosq News 33: 195-198.

11. Kalra NL, 1978. National Malaria Eradication Programme, India - its problems, management and research needs. J Commun Dis 10: 1-20.

12. Kalra NL, 1980. Emergence of malaria zoonosis of simian origin as natural phenomenon in Greater Nicobars, Andaman and Nicobar Islands - a preliminary note. J Commun Dis 12: 49-54.

13. Meek SR, 1995. Vector control in some countries of Southeast Asia: comparing the vectors and the strategies. Ann Trop Med Parasitol 89: 135-147.

14. Nguyen Tang Am, Le Quy R, Vu Thi H, Nguyen Bieh L, 1993. Entomo-epidemiological studies of malaria in the coastal zone of Ho Chi Minh City 1990-1992. Santé 3: 464-473.

15. Soeparmo HT, Lair RL, 1954. Anopheles sundaicus and its Control by DDT Residual House Spraying in Indonesia. Geneva: World Health Organization. Malaria Conference for the Western Pacific and South East Asia Regions. WHO/Mal 118.

16. Chow CY, 1970. Bionomics of malaria vectors in the western Pacific region. Southeast Asian J Trop Med Public Health 1: $40-57$.

17. Chowanadisai L, Krairiksh S, Thanasripukdikul S, 1989. Microbial control of Anopheles sundaicus, a malaria vector in Thailand, by Bacillus sphaericus 2362. Mosq Borne Dis Bull 6: 3944.

18. Harinasuta C, Guptavanij P, Vasuvat C, 1974. Studies on the medical ecological epidemiology in mangrove areas in Thailand. Southeast Asian J Trop Med Public Health 5: 105-127.

19. Klein JM, 1977. The mosquito fauna of Cambodia. I. Anophelinae (Diptera, Culicidae). Cah ORSTOM Ser Entomol Med Parasitol 15: 107-122.

20. Tin O, Pe Thet H, Khin Thet W, Parks W, Bryan J, 2001. Gender, mosquitoes and malaria: implications for community development programs in Laputta, Myanmar. Southeast Asian J Trop Med Public Health 32: 588-594.

21. Ikemoto T, 1996. Ecological diversities of Anopheles sundaicus as a vector mosquito of malaria. Med Entomol Zool 47: 1-13.

22. Chang MS, Linton YM, Harbach RE, 2001. The Anopheles sundaicus species complex - a preliminary study of larval ecology from two sites in Sarawak, Malaysia. Mekong Malaria Forum 8: 91-95.

23. Rao TR, 1984. The Anophelines of India. Delhi: Malaria Research Centre, Indian Council of Medical Research.

24. Sukowati S, Baimai V, Andris H, 1996. Sex chromosome variation in natural populations of the Anopheles sundaicus complex from Thailand and Indonesia. Mosq Borne Dis Bull 13: $8-13$.

25. Sukowati S, Baimai V, Harun S, Dasuki Y, Andris H, Efriwati M, 1999. Isozyme evidence for three sibling species in the Anopheles sundaicus complex from Indonesia. Med Vet Entomol 13: 408-414.

26. Linton YM, Harbach RE, Chang MS, Anthony TG, Matusop A, 2001. Morphological and molecular identity of Anopheles (Cellia) sundaicus (Diptera: Culicidae), the nominotypical member of a malaria vector species complex in Southeast Asia. Syst Entomol 26: 357-366.

27. Reid JA, 1968. Anopheline mosquitoes of Malaya and Borneo. Studies from the Institute of Medical Research Malaysia 31. Kuala Lumpur, Malaysia: Government of Malaysia.
28. Collins RT, Jung RK, Anoez H, Sutrisno RH, Putut D, 1979. A Study of the Coastal Malaria Vectors, Anopheles sundaicus (Rodenwaldt) and Anopheles subpictus Grassi, in South Sulawesi, Sulawesi, Indonesia. Geneva: World Health Organization. WHO/Mal 79.

29. Coosemans M, Cong D, Socheat D, Inthakone S, Baimai V, Manguin S, Harbach RE, 1998. Identification and Characterization of Malaria Vectors in Southeast Asia: A Prerequisite for Appropriate Vector Control. Antwerp, Belgium: Institute of Tropical Medicine. INCO-DEC report, ERBIC18.CT.970211.

30. Phan VT, 1998. Epidémiologie du Paludisme et Lutte Antipaludique au Vietnam. Hanoi: Edition Médicales Vietnam.

31. Nagpal BN, Kalra NL, 1997. Malaria vectors of India. J Parasitic Dis 21: 105-112.

32. Christophers SR, 1933. Fauna of British India, including Ceylon and Burma. Volume IV. Diptera. Family Culicidae. Tribe Anophelini. London: Taylor \& Francis.

33. Nasiruddin M, 1952. A note on the natural infectivity of mosquitoes in East Pakistan. Pakistan J Health 2: 113-115.

34. Puri IM, 1936. The distribution of anopheline mosquitoes in India: Additional records, 1931-1935. Rec Malaria Surv India 6 : 177-211.

35. Puri IM, 1948. The distribution of anopheline mosquitoes in India, Pakistan, Ceylon and Burma: Part V: additional records, 1936-1947. Indian J Malariol 6: 177-211.

36. Singh N, Nagpal BN, Sharma VP, 1985. Mosquitoes of Kutch, Gujarat. Indian J Malariol 22: 17-20.

37. Dash AP, Behura BK, Roy JR, 1984. On the distribution of anopheline mosquitoes in Orissa, India. J Zool Soc India 36: $1-14$.

38. Rajogopal R, 1976. Studies on persistent transmission of malaria in Burnihat, Meghalaya. J Commun Dis 8: 235-245.

39. Dash AP, Hazra RK, Mahapatra N, Tripathy HK, 2000. Disappearance of malaria vector Anopheles sundaicus from Chilika Lake area of Orissa State in India. Med Vet Entomol 14: 445449.

40. Sandosham AA, Thomas V, 1983. Malariology: With Special Reference to Malaya. Singapore. Singapore University Press.

41. Abu Hassan A, Rahman WA, Che Salmah MR, Rashid MZA, Jaal Z, Adanan CR, Shahrem MR, 1997. The distribution of common Anopheles mosquitoes in northwestern Peninsular Malaysia. J Vect Ecol 22: 109-114.

42. Ikemoto T, Sumitro, Panjaitan W, Shibuya T, 1986. Laboratory and small-scale field tests of larvicides and larvivorous fishes against Anopheles sundaicus larvae at Perupuk Village, North Sumatra, Indonesia. Jpn J Sanit Zool 37: 105-112.

43. Scanlon JE, Reid JA, Cheong WH, 1968. Ecology of Anopheles vectors of malaria in the oriental region. Cah ORSTOM Ser Entomol Med Parasitol VI: 237-246.

44. Soerono M, Davidson G, Muir DA, 1965. The Development and trend of insecticide-resistance in Anopheles aconitus Dönitz and Anopheles sundaicus Rodenwalt. Bull World Health Organ 32: 161-168.

45. van der Brug PH, 1997. Malaria in Batavia in the 18th century. Trop Med Int Health 2: 892-902.

46. Das MK, Nagpal BN, Sharma VP, 1998. Mosquito fauna and breeding habitats of anophelines in Car Nicobar Island, India. Indian J Malariol 35: 197-205.

47. Kirnowardoya S, Yoga GP, 1987. Entomological investigations of an outbreak of malaria in Chilacap on south coast of central Java, Indonesia during 1985. J Commun Dis 19: 121-127.

48. Miyagi I, Toma T, Mogi M, Martono, Yotopranoto S, Arifin Z, Dachlan Y, 1994. Mosquitoes species (Diptera: Culicidae) from Lombok Island, Indonesia. Mosq Syst 26: 19-24.

49. Webster J, 2000. Malaria Consortium - Cambodia: Roll Back Malaria Complex Emergencies Technical Support Network. Liverpool, United Kingdom: Liverpool School of Tropical Medicine.

50. Senior-White R, Adhikari AK, 1939. On malaria transmission around the Chilika lake. J Mal Inst India 2: 395-423.

51. Reid JA, 1966. A note on Anopheles subpictus Grassi and $A$. indefinitus Ludlow (Diptera: Culicidae). J Med Entomol 3: 327-331.

52. Kikuchi T, Takagi M, Tokuhisa E, Suzuki T, Panjaitan W, Yasuno M, 1997. Water hyacinth (Eichhornia crassipes) as an 
indicator to show the absence of Anopheles sundaicus larvae. Med Entomol Zool 48: 11-18.

53. Imai C, Ikemoto $\mathrm{T}$, Takagi $\mathrm{M}$, Yamugi $\mathrm{H}$, Pohan $\mathrm{W}$, Hasibuan $\mathrm{H}$, Sirait H, Panjaitan W, 1988. Ecological study of Anopheles sundaicus larvae in a coastal village of North Sumatra, Indonesia. I. Topography, land use, and larval breeding. Jpn J Sanit Zool 39: 293-300.

54. Schaefer $\mathrm{CH}$, Kirnowardoyo S, 1983. An operational evaluation of Bacillus thuringiensis serotype $\mathrm{H}-14$ against Anopheles sundaicus in West Java, Indonesia. Mosq News 43: 325-328.

55. Iyenger MOT, 1945. Naturalistic methods of control of breeding of Anopheles sundaicus by means of Eichhornia. J Mal Inst 6: 309-310.

56. Sundaraman S, Soeroto RM, Siran M, 1957. Vectors of malaria in mid-Java. Indian J Malariol 11: 321-338.

57. Nanda N, Das MK, Wattal S, Adak T, Subbarao SK, 2004. Cytogenetic characterization of Anopheles sundaicus (Diptera: Culicidae) population from Car Nicobar Island, India. Ann Entomol Soc Am 97: 171-176.

58. Dusfour I, Linton YM, Cohuet A, Harbach RE, Baimai V, Trung HD, Chang MS, Matusop A, Manguin S, 2004. Molecular evidence of speciation between island and continental populations of Anopheles (Cellia) sundaicus (Diptera: Culicidae), a principal malaria vector raxon in Southeast Asia. J Med Entomol 41: 287-295.

59. Gould DJ, Scanlon JE, Major MSC, Ward RA, 1966. Anopheles Vectors of Malaria in Southeast Asia. Washington, DC: Army Science Conference Proceedings, 361-373.

60. Sen P, 1938. Anopheles sundaicus (Ludlowi) and malaria in Calcutta. J Mal Inst India l 1: 83-107.

61. Kumari R, Joshi H, Giri A, Sharma VP, 1993. Feeding preferences of Anopheles sundaicus in Car Nicobar Island. Indian J Malariol 30: 201-206.

62. Huehne WH, 1971. Experience with an insecticide-drug combination and observations on suppressive chloroquine-pyrimethamine treatment. J Trop Med Hyg 74: 110-116.

63. Coosemans M, Wery M, Mouchet J, Carnevale P, 1992. Transmission factors in malaria epidemiology and control in Africa. Mem Inst Oswaldo Cruz 87 (Suppl 3): 385-391.

64. Poolsuwan S, 1995. Malaria in prehistoric Southeastern Asia. Southeast Asian J Trop Med Public Health 26: 3-22.

65. Collins WE, Contacos PG, 1980. Infection and transmission studies with Plasmodium gonderi in the Macaca mulatta monkey. $J$ Parasitol 66: 998-1002.

66. Kirnowardoyo S, 1988. Anopheles malaria vector and control measures applied in Indonesia. Southeast Asian J Trop Med Public Health 19: 713-716.

67. Takagi M, Pohan W, Hasibuan H, Panjaitan W, Suzuki T, 1995. Evaluation of shading of fish farming ponds as a larval control measure against Anopheles sundaicus Rodenwaldt (Diptera: Culicidae). Southeast Asian J Trop Med Public Health 26: 748 753.

68. Imai C, Yamugi H, Panjaitan W, 1987. Efficacy of several larvicides in laboratory and field tests against Anopheles sundaicus in a village, North Sumatra, Indonesia. Jpn J Sanit Zool 38: 93-102.
69. Manguin S, Roberts DR, Peyton EL, Rejmankova E, Pecor J, 1996. Characterization of Anopheles pseudopunctipennis larval habitats. J Am Mosq Control Assoc 12: 619-626.

70. Covell G, 1927. Report on an Inquiry into Malarial Conditions in the Andamans. Delhi: Government of India Press.

71. Covell G, Singh P, 1942. Malaria in the coastal belt of Orissa. $J$ Malaria Inst India 4: 457-488.

72. Kumari R, Sharma VP, 1994. Resting and biting habits of Anopheles sundaicus in Car Nicobar Island. Indian J Malariol 31: 103-114.

73. Nandi J, Kaul SM, Sharma SN, Shiv L, 2000. Anthropophily of anophelines in duars of West Bengal and other regions of India. J Commun Dis 32: 95-99.

74. Ikemoto T, 1982. Studies on the bionomics of An. sundaicus (Rodenwaldt, 1925), the principal malaria vector in a coastal area of the North Sumatra, Indonesia. Teikyo Med J 5: 1-15.

75. Akiyama J, 1984. Assignment Report (Jan 1980-Dec 1983). Jakarta: Indonesia. Malaria Control Program in Indonesia.

76. Moorhouse DE, Wharton RH, 1965. Studies on Malayan vectors of malaria; methods of trapping and observations on biting cycles. J Med Entomol 1: 359-370.

77. Giang NL, Hoa PT, Dan BV, Thang TT, 1980. Quelques Particularités du Paludisme au Pilote Ayant An. sundaicus et Les Mesures Appliquées. Hanoi, Vietnam: National Institute of Malariology, Parasitology and Entomology, 59-65.

78. Bonne-Webster J, Swellengrebel NH, 1953. The Anopheline Mosquito of the Indo-Australian Region. Amsterdam: De Bussy.

79. Marwoto HA, Arbani PR, 1991. Forest Malaria in Indonesia. Geneva: World Health Organization. Forest Malaria in Southeast Asia: Proceedings of an Informal Consultative Meeting. WHO/MRC.

80. Hien NT, 1968. The Genus Anopheles in the Republic of Vietnam. Saigon, Vietnam: National Malaria Program.

81. Crandell HA, 1954. Resistance of An. sundaicus to DDT. a preliminary report. Mosq News 14: 194-195.

82. WHO, 1976. Resistance of vectors and reservoirs of disease to pesticides. 22th Report of the WHO Expert Committee on Insecticides. World Health Organ Tech Rep Ser 585.

83. Ong Keng Ho, Chewlai M, Lok CL, 1981. Current insecticidal susceptibility status of mosquitoes in Singapore. Southeast Asian J Trop Med Public Health 12: 222-227.

84. Kirnowardoyo S, 1985. Status of Anopheles malaria vectors in Indonesia. Southeast Asian J Trop Med Public Health 16: 129132.

85. Gornostaeva RM, Vu Tkhin V, Nguen Van C, Nguen Tkhyong K, Nguen Suan Z, Nguen Tuan R, Nguen Tho V, 1994. Sensitivity of malarial mosquitoes to insecticides in Vietnam. Med Parazitol (Mosk) 34-41.

86. Webster J, 2000. Malaria Consortium - East Timor: Roll Back Malaria Complex Emergency Malaria Technical Support. Liverpool, United Kingdom: Liverpool School of Tropical Medicine.

87. Imai C, Panjaitan W, 1990. Ecological study of Anopheles sundaicus larvae in coastal village of North Sumatra, Indonesia. II. Environmental factor affecting larval density of An. sundaicus and other anopheline species. Jpn J Sanit Zool 41: 205-211. 